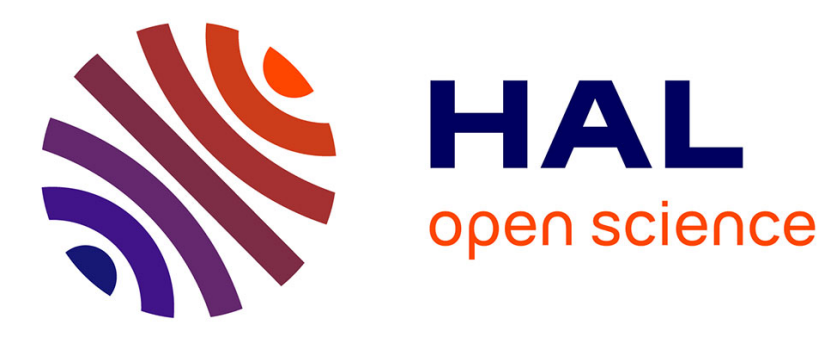

\title{
Management of Giant Thoracic Disc Herniation by Thoracoscopic Approach: Experience of 53 Cases
}

David Brauge, Catherine Horodyckid, Marta Arrighi, Vincent Reina, Christophe Eap, Etienne Mireau, Bertrand Baussart, Sorin Aldea, Stephan Gaillard

\section{To cite this version:}

David Brauge, Catherine Horodyckid, Marta Arrighi, Vincent Reina, Christophe Eap, et al.. Management of Giant Thoracic Disc Herniation by Thoracoscopic Approach: Experience of 53 Cases. Operative Neurosurgery, 2019, 16 (6), pp.658-666. 10.1093/ons/opy250 . hal-02944019

\section{HAL Id: hal-02944019 https://hal.science/hal-02944019}

Submitted on 21 Sep 2020

HAL is a multi-disciplinary open access archive for the deposit and dissemination of scientific research documents, whether they are published or not. The documents may come from teaching and research institutions in France or abroad, or from public or private research centers.
L'archive ouverte pluridisciplinaire HAL, est destinée au dépôt et à la diffusion de documents scientifiques de niveau recherche, publiés ou non, émanant des établissements d'enseignement et de recherche français ou étrangers, des laboratoires publics ou privés. 


\section{Management of Giant Thoracic Disc Herniation by Thoracoscopic Approach: Experience of 53 Cases}

\author{
David Brauge, MD*\# \\ Catherine Horodyckid, MD* \\ Marta Arrighi, MD* \\ Vincent Reina, MD* \\ Christophe Eap, MD* \\ Etienne Mireau, MD* \\ Baussart Bertrand, MD* \\ Sorin Aldéa, MD* \\ Stephan Gaillard, MD* \\ *Service de Neurochirurgie, Hôpital \\ Foch, Suresnes, France; ${ }^{\ddagger}$ Institut de \\ Biomécanique Humaine Georges \\ Charpak, Arts et Métiers Paris Tech, Paris, \\ France \\ Correspondence: \\ Brauge David, MD \\ Service de Neurochirurgie, \\ Hôpital Foch, \\ 40 rue Worth, \\ 92150 Suresnes, France. \\ E-mail: brauge.d@chu-toulouse.fr
}

BACKGROUND: Giant thoracic disc herniation (gTDH) is a rare condition. It is defined by a herniation that occupies at least $40 \%$ of the thoracic spinal canal and is usually calcified. Several surgical techniques have been described to date but this surgery remains a technically difficult procedure.

OBJECTIVE: To report the long-term outcome of 53 patients with myelopathy due to gTDH who were operated on by a thoracoscopic approach. The technical details of the preoperative assessment and the surgical procedure are presented.

METHOD: We present a retrospective study of a database of 53 patients operated for symptomatic $\mathrm{gTDH}$ by a thoracoscopic approach. The following clinical parameters were assessed initially and used during follow-up: Frankel grade and JOA score adapted to the thoracic spine ( $\mathrm{mJOA})$, pain in the lower limbs and limitation of the walking perimeter to less than 500 meters. The quality of spinal cord decompression was assessed postoperatively by magnet resonance imaging (MRI).

RESULTS: The mean follow-up was 78.1 mo (SD 49.4). At the last follow-up visit, clinical examination showed a mean improvement of 0.91 Frankel grade $(P<.001)$ and $2.56 \mathrm{mJOA}$ score respectively $(P<.001)$. Lower limb pain and walking perimeter were also improved. Postoperative MRI revealed that the resection was complete in 35 cases, subtotal in 13 cases, and incomplete in 5 cases.

CONCLUSION: gTDH is a condition that often evolves favorably after surgery. The thoracoscopic approach is a feasible alternative technique.

KEY WORDS: Giant, Intervertebral disc, Myelopathy, Thoracic disc, Thoracic disc herniation, Thoracoscopy
$\mathbf{T}$ horacic disc herniation (TDH) is a frequent anatomic lesion that affects $11 \%$ to $14.5 \%$ of the population. ${ }^{1}$ Symptomatic TDHs are extremely rarer, estimated at 1 case per million. ${ }^{2}$ Hott et $\mathrm{al}^{3}$ defined herniation occupying more than $40 \%$ of the spinal canal as a special condition called giant thoracic disc herniation (gTDH). A study of the literature series on this topic shows that this pathology is most often revealed by a progressive myelopathy. In the vast majority of

ABBREVIATIONS: CSF, cerebrospinal fluid; gTDH, giant thoracic disc herniation; MRI, magnet resonance imaging; TDH, thoracic disc herniation cases, this lesion is calcified. ${ }^{4-10}$ Although there is a consensus in favor of surgical treatment in cases of proven myelopathy, several options are described for the treatment of these patients. Since the posterior approach via laminectomy is associated with a high morbidity, the transthoracic access has become a standard procedure. Rosenthal and colleagues ${ }^{11,12}$ first described an endoscopic procedure to remove the herniation by an anterior approach, which provides good results. However, to date, few authors have studied the feasibility and interest of thoracoscopy in the removal of gTDH. We report a series of 53 patients treated for this condition by an endoscopic procedure. The aim of this article is to present the results of the treatment of this disease on a large series and to detail the technical nuances of the management of gTDH by thoracoscopic approach. 


\section{METHODS}

\section{Design}

We present a retrospective study based on a prospective database of patients treated for TDH between May 2001 and September 2016. All patients were operated by the same surgeon.

\section{Study Population}

Our series consisted of 53 patients, whose preoperative clinical characteristics are detailed in Table 1 . Thirty-nine patients had preoperative limitation of their walking distance: This was assessed by the following question: "how many meters can you walk on a flat ground?" We considered the patient was limited if he could not walk more than 500 meters. Surgical treatment was offered in cases of initial severe myelopathy or deterioration of the neurological status during followup. For patients with only slight symptoms at the time of the discovery of the herniation, the motor and somatosensory evoked potentials were recorded to search for an infra-clinical myelopathy. In this case, the surgical indication was considered if electrophysiological monitoring revealed new degradation during follow-up. In our team, an endoscopic approach is always considered first except in cases with histories of pleural pathologies. All our patients had a computed tomography scan and magnetic resonance imaging (MRI) in the preoperative stage. These two examinations allowed us to appreciate the calcified nature of the herniation and its impact on the spinal cord. The distribution of the lesions is illustrated in Figure 1. One patient was operated at 2 levels during the same operative time. Radiological data are listed in Table 1. Spinal cord arteriography was performed in all cases in order to identify afferent arteries to the anterior spinal arterial axis. This information was taken into account in the surgical planning.

\section{Operative Technique for Giant TDH}

The main steps of this surgery are similar to that of an open approach. The patient is placed in lateral decubitus with an axillary roll and all pressure points are padded. The side of approach is determined by the lateralization of the herniation, the presence of an arterial supply to the anterior spinal axis on the spinal cord angiogram, and the situation of the aorta if a left thoracoscopy is considered. The procedure is performed under general anesthesia and requires ipsilateral pulmonary exclusion. All patients of our series received intravenous methylprednisolone during surgery (on average $240 \mathrm{mg}$ of methylprednisolone). The main operator faces the patient and his assistant is positioned at the patient's back (see Video, Supplemental Digital Content). The spinal level is determined in two ways: the first registration was originally performed preoperatively by placing a metal marker during a preoperative scan, the second check being performed at the beginning of the procedure by endopleural counting of the ribs. Since September 2010, the preoperative installation of a radio opaque marker has been replaced by perioperative Multiplan acquisition (O-Arm). Classically, 4 working channels are used: 1 for the camera, 2 operator channels, and 1 retractor for the pulmonary parenchyma or the diaphragm according to the treated level. The posterior parietal pleura are incised with the monopolar on the lower border of the rib's head. The intercostal vascular pedicle is coagulated and sectioned if it does not supply the spinal cord. Bone resection begins with the resection of the lower rib head. In our first cases, bone drilling began at the pedicle but the technique was later modified and the opening of the canal is now performed only at the end, after resection of the vertebral plates on both sides of the herniation in an oblique plane over the entire height of the herniation in the sagittal plane. Bone drilling may be extended to the contralateral pedicle depending on the width of the herniation. Drilling is planned according to the height of the herniation and must be large enough to allow visualization of the entire ventral dura. Finally, the herniation is retracted anteriorly into the drilled cavity. An illustration of the steps of bone resection is given in Figure 2, while Figure 3 illustrates the modification adopted since 2006. Once the posterior longitudinal ligament has been exposed, it is sharply opened, giving access to the anterior and lateral face of the dura. The herniation then becomes slightly more mobile and its excision is most often carried out by fragmentation using micro-instruments dedicated to endoscopy

TABLE 1. Preoperative Clinical and Radiological Data of our Study Population

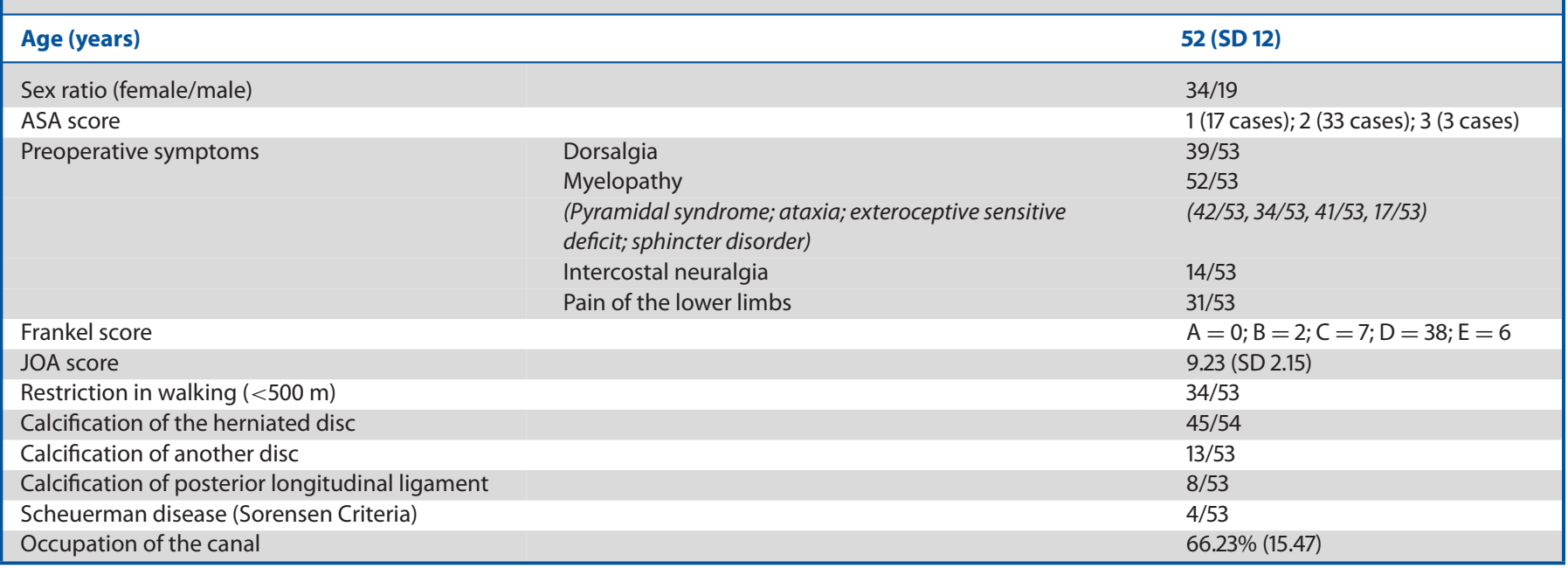



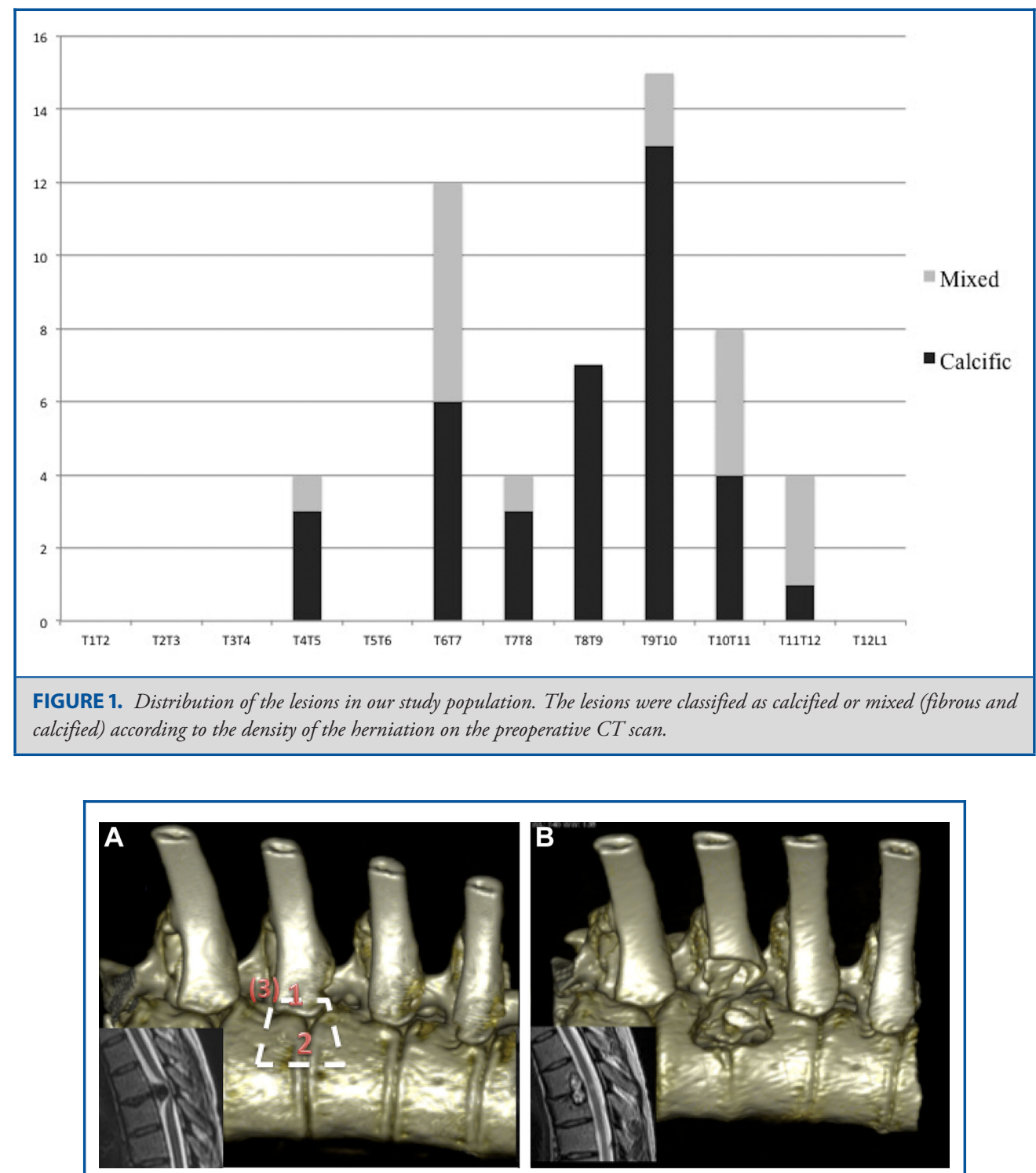

FIGURE 2. A 31-yr-old female patient with walking instability evolving for 3 mo. On examination, she presented pyramidal signs and ataxia. She reported recent sphincter disturbances. Spinal MRI showed a large T6T7 herniation occupying $90 \%$ of the canal. Surgery allowed subtotal resection. A, CT scan reconstruction explaining the different steps of bone resection, beginning with the removal of the head of the rib (1). Bone drilling is then continued on either side of the herniation (2). The extension to the pedicle is optional depending on the extent of the herniation (3). B, Appearance of the bone cavities at the end of the operation.

(hook, spatula, rongeur). In cases of transdural passage/very voluminous herniation and difficult to dissect from the posterior common vertebral ligament, a partial removal may be performed. This consists of a resection that is as wide as possible, allowing spinal cord decompression. If the herniation can be dissected and mobilized, it is resected and the dura reconstructed using a pleural flap or fascia lata maintained by biological glue. Osteosynthesis is performed when the bone resection extends over more than $50 \%$ of the surface of the vertebral body. In this case, a cage filled with bone substitute is fitted in place of the cavity. This cage is introduced into the pleural cavity via a trocar orifice. The osteosynthesis is performed by vertebral body screws that are connected by a rod or a lateral plate (Figure 4 and example 1 in Video, Supplemental Digital Content). The pleural cavity is then abundantly washed with saline and pulmonary re-expansion is carried out under visual monitoring by the operator, leaving an aspirative drain that will allow the exsufflation of the pleural cavity. If the operator detects a dural tear during surgery, no 


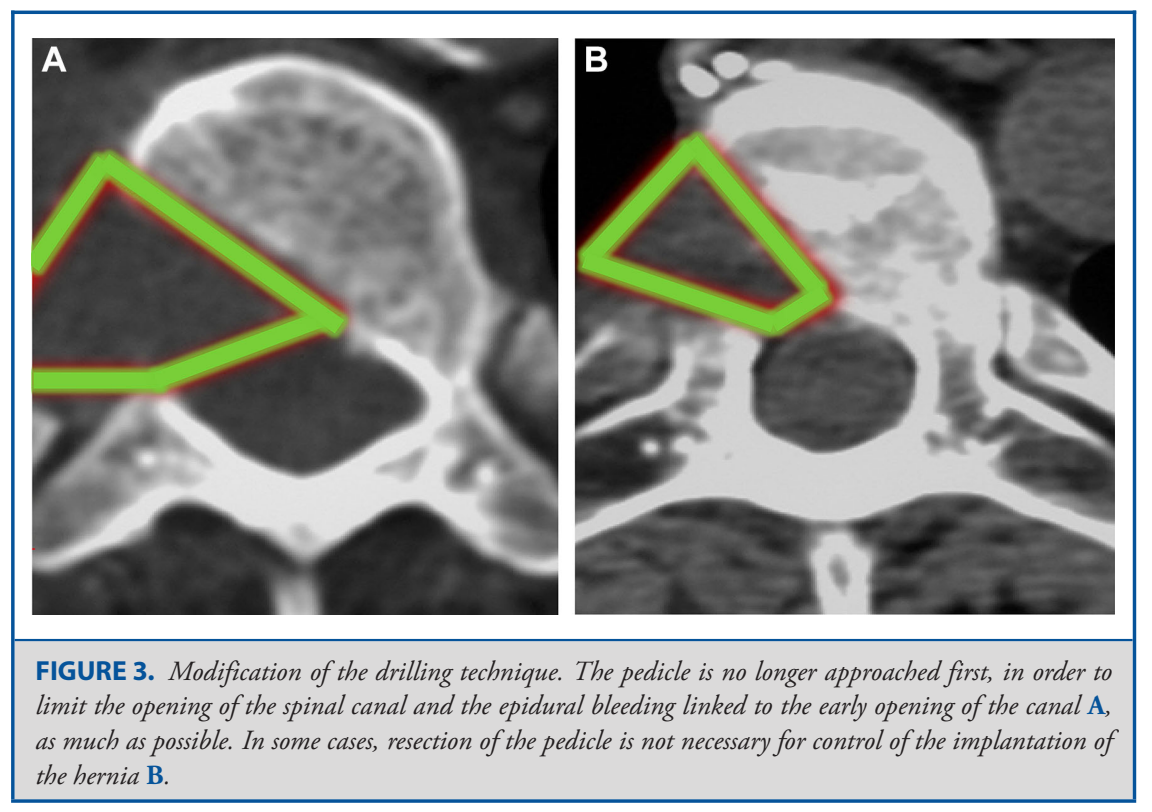

drain is left in place. The drain is removed on the second postoperative day. Postoperative care consists of close monitoring of the neurological and respiratory functions. The patient is mobilized early with rehabilitation work by the physiotherapist. A chest X-ray is systematically taken just after surgery and on a regular basis during the hospital stay. Discharge is considered from the fifth postoperative day in uncomplicated cases.

\section{Evaluation Criteria}

Long-term follow-up was conducted by telephone interview or mail. Eleven percent of patients in the study did not respond to mail or phone inquiries. For those patients, we used the clinical data at the last consultation and this decreased the duration of follow-up.

Clinical follow-up was done by the senior author and 2 junior surgeons qualified in the review of clinical and radiological data concerning spinal surgery. The surgical procedure was evaluated on the following criteria: duration $(\mathrm{min})$, blood loss $(\mathrm{mL})$, the preoperative and postoperative walking perimeter, lower limb pain (described by the patient himself as improvement, stability, or aggravation compared to preoperative status), Frankel grade and the JOA score adapted to the thoracic spine (mJOA; Table 2), the length of stay, the extent of drilling, and complications. Based on postoperative radiological data, we classified resections as total, subtotal (residual $<10 \%$ of initial volume), incomplete (residual $>10 \%$ ), or impossible. The reappearance of a perimedullary cerebrospinal fluid (CSF) and the presence of a T2 sequence hypersignal on postoperative MRI were also recorded.

\section{Statistical Analysis}

For descriptive analysis, quantitative variables were described with standard means and deviations if they were normally distributed. Qualitative variables were described with numbers and percentages. Comparison of the pre- and postoperative neurological status using the mJOA score and Frankel grade relied on a Student's $t$-test. The primary endpoint was clinical neurological improvement defined by improvement of at least 1 Frankel grade. In order to identify predicting factors for postoperative improvement, a univariate analysis was planned by logistic regression and allowed rough odds ratios to be obtained for each of these variables, with their associated $P$ values. The odds ratios were adjusted for gender and age and obtained by multiple logistic regression for each of these variables with their $P$ values. An association was considered significant if $P<.05$. R software was used for all these calculations. The entire statistical analysis was performed by an independent statistician.

\section{Ethics Considerations}

This study was approved by the local ethics committee (IRB number: CERC-SFCTCV-2017-8-1-14-41-45-brda). The clinical trial registration number is NCT03295617. All patients agreed to anonymous use of medical data for research purposes.

\section{RESULTS}

The outcomes and results are listed in Table 3. In 10 patients, surgical revision was necessary for dural repair ( 5 cases), level error ( 2 cases), residual compression ( 1 case), premature termination of the first procedure due to high blood loss (1 case), or exploration of pleural effusion (1 case). Eight patients had a new neurological deficit, for which the recovery time varied from a few hours to a few days under high dose corticosteroid therapy. Two patients had permanent neurological worsening after surgery, including 1 case of total paraplegia. Other postoperative complications were: intrathoracic collection of CSF ( 5 cases), infectious spondylodiscitis (1 case), noninfectious pleurisy (1 case), pulmonary embolism (1 case), superficial sepsis (1 case), and postoperative kyphosis (1 case). All these situations were treated successfully. The cases of CSF leak are detailed in Table 4 . Of the 50 cases with postoperative MRI, there was only 1 case in which there was no reappearance of a perimedullary CSF spaces. This patient received 


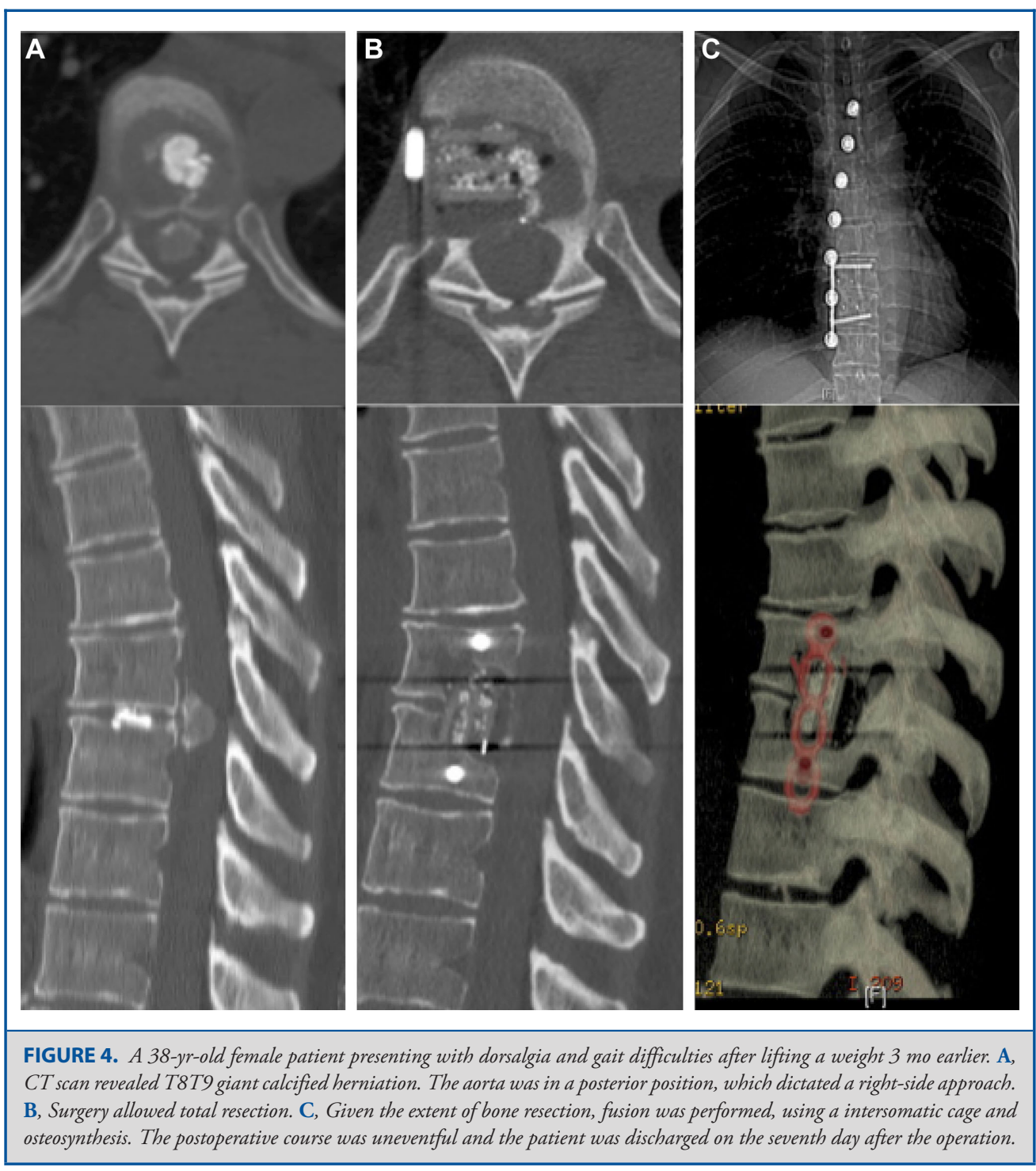

complementary laminoarthrectomy and arthrodesis by posterior approach $5 \mathrm{mo}$ after his first operation because of his incomplete neurological recovery. In 18 cases, an intramedullary hypersignal was observed in the T2 sequence of the postoperative MRI. The existence of a good outcome defined by an improvement of at least 1 Frankel grade was associated with a preoperative Frankel score $(\mathrm{OR}=0.523 ; P=.012)$, and presence of intercostal neuralgia $(\mathrm{OR}=0.02157 ; P=.04)$. A preoperative motor deficit was associated with worse outcome $(\mathrm{OR}=12.6635 ; P=.002)$.

\section{DISCUSSION}

\section{Decision Criteria for Surgical Treatment in Case of gTDH}

Calcific TDH is one of the most dangerous procedures in spine surgery. To perform it by thoracoscopy requires extensive experience. If endoscopy is considered less invasive, the wish to diminish the surgical trauma should not lead to an undertreatment of the affection. For this reason, this surgery should be performed only by surgeons with solid experience in endoscopic surgery, in centers with large experience. For other cases, mini open approach seems to provide an acceptable alternative. ${ }^{8,9,13}$ In case of disabling myelopathy, it seems logical to offer surgery. Surgical treatment may be more difficult to decide in cases of a large lesion in an asymptomatic patient: some will evolve towards a progressive myelopathy, while others will remain asymptomatic. In rare cases, these lesions may resolve spontaneously and no predictive factors have been precisely identified. ${ }^{14}$ For asymptomatic lesions, our attitude is to carry out regular neurological, radiological, and electrophysiological monitoring as it has been proven that electrophysiological degradation precedes 


\section{TABLE 2. mJOA Scale as Used in the Present Study}

Motor dysfunction (lower extremities)

\begin{tabular}{cl}
0 & Complete loss of motor and sensory function \\
1 & Sensory preservation without ability to move legs \\
2 & Able to move legs but unable to walk \\
3 & Able to walk on flat floor with a walking aid \\
4 & Able to walk up and/or down stairs with hand rail \\
5 & Moderate to significant lack of stability but able to walk up and/or down stairs without hand rail. \\
6 & Mild lack or stability but walk unaided with smooth reciprocation \\
7 & No dysfunction \\
Sensation (lower extremities) & Complete loss of sensation \\
0 & Severe sensory loss or pain \\
1 & Mild sensory loss \\
2 & No sensory loss \\
Sphincter function & Inability to micturate \\
0 & Marked difficulty with micturition or partial incontinence \\
1 & Mild to moderate difficulties with micturition or mild incontinence \\
2 & Normal micturition \\
\hline
\end{tabular}

\section{TABLE 3. Results of Surgery}

\begin{tabular}{|c|c|c|c|}
\hline Type of data & & Results & Pre vs post op \\
\hline \multirow{4}{*}{ Surgical data } & Transdural herniation & $18 / 53$ & \\
\hline & Duration of surgery (min) & 229.15 (SD 58.33) & \\
\hline & Surface of drilling cavities (\%) & 31.70 (SD 13.93) & \\
\hline & Anterior arthrodesis & $6 / 45$ & \\
\hline \multirow[t]{4}{*}{ Postoperative data } & $\begin{array}{l}\text { Quality of resection }{ }^{\text {a }} \text { : } \\
\text { total, subtotal, incomplete }\end{array}$ & $36 / 54 ; 13 / 54 ; 05 / 54$ & \\
\hline & $\begin{array}{l}\text { Intramedullary hypersignal on } \\
\text { T2-weighted MRI }^{\mathrm{b}}\end{array}$ & $18 / 50$ & \\
\hline & $\begin{array}{l}\text { Reappearance of perimedullary CSF } \\
\text { on postop } \mathrm{MRI}^{\mathrm{C}}\end{array}$ & $49 / 50$ & \\
\hline & Duration of hospitalization (d) & 10.09 (SD 5.57) & \\
\hline \multirow[t]{5}{*}{ Outcome data } & Follow-up (mo) & 78.1 (SD 49.4) & \\
\hline & $\begin{array}{l}\text { Evolution of mJOA score } \\
\text { Improvement, stabilization, } \\
\text { aggravation }\end{array}$ & $50 / 53 ; 1 / 53 ; 2 / 53$ & \\
\hline & Walking limitation below $500 \mathrm{~m}$ & $9 / 53$ & \\
\hline & $\begin{array}{l}\text { Pain in lower limbs }{ }^{c} \\
\text { Improvement, stabilization, } \\
\text { aggravation }\end{array}$ & $29 / 31 ; 2 / 31 ; 0 / 31$ & \\
\hline & $\begin{array}{l}\text { Reported pain on the parietal } \\
\text { approach }\end{array}$ & $12 / 53$ & \\
\hline
\end{tabular}

${ }^{a}$ One patient was operated at two levels.

${ }^{b}$ Postoperative MRI was not possible in 3 cases, resection was evaluated on CT-scan.

'Thirty-one patients complained about pain before surgery. 
TABLE 4. Cases of Patients Reoperated on for CSF Leak

\begin{tabular}{|llll|}
\hline Patient & Symptoms & Delay (d) & Surgical treatment \\
\hline 1 & Dyspnea & 114 & Facia lata + biological glue \\
18 & $\begin{array}{l}\text { Muscle in the bony cavities } \\
\text { scan symptoms (2 postoperative CT } \\
\text { Headache }\end{array}$ & 63 & $\begin{array}{l}\text { Facia lata + biological glue } \\
\text { Muscle in the bony cavities }\end{array}$ \\
43 & Headache & 11 & $\begin{array}{l}\text { Facia lata + biological glue } \\
\text { Muscle in the bony cavities }\end{array}$ \\
48 & 11 & $\begin{array}{l}\text { Facial lata + biological glue and } \\
\text { tachosil (Takeda Austria GmbH: } \\
\text { Linz, Austria) }\end{array}$ \\
\hline
\end{tabular}

clinical degradation for degenerative pathologies with spinal cord stenosis. ${ }^{15}$ The addition of an anterior arthrodesis is variable in the literature. Our attitude is to fuse it if more than $50 \%$ of the surface of the vertebral plate has been drilled, since biomechanical studies show a correlation between the extent of vertebral body damage and instability. ${ }^{13,16,17}$ The decision for complementary arthrodesis was thus taken during the operation, according to the size of the bone resection. Since September 2010, perioperative Multiplan acquisition by $\mathrm{O}$-arm has allowed the extent of the bone resection to be ascertained as this was previously described by other authors. ${ }^{18}$ This device also helps us at the beginning of the surgery for the identification of the level. The 2 cases of level error occurred prior to the acquisition of this tool.

\section{Outcome Measures}

Many authors have published data about surgery of TDH but few series have focused on giant TDH. It is a rare clinical entity, the surgical difficulty of which is greatly affected by its calcified nature and the large volume of the herniated disc. Given that these patients tend to present with myelopathy and an already compromised spinal cord, careful planning of the procedure is critical. Table 5 lists previously published series. To the best of our knowledge, we report the largest series of patients operated for gTDH by thoracoscopy. The majority of authors use the mJOA score, ASIA score or Frankel grade to evaluate postoperative findings. In order to obtain a more complete view, we used other parameters, such as walking limitation, as some patients for whom no problem is revealed during consultation may nevertheless be limited after several minutes of walking. Other factors, such as the presence of pain in the lower limbs, are not mentioned in the literature. This pain, due to spinal cord compression, could lead to surgery, given that it is refractory to any treatment. In our series, $58 \%$ of the patients complained of painful symptoms in the lower limbs and this was the main reason for consultation in 13\% of the cases. Although the endoscopic approach is considered less invasive, some of our patients reported parietal pain related to the surgical approach. This was greatly improved in the second part of our experience by employing a single-use flexible trocar. Like other authors, we find that one important prognostic factor is the severity of the initial myelopathy.

The influence of neuralgia is more surprising. In fact, we think that patients who have this symptom come to consult earlier, when their myelopathy is less severe.

Another possible explanation is that those herniation are more lateralized and easier to access.

The presence of a transient neurological worsening is of classic finding in the surgery of tumors or vascular malformation of the thoracic spinal cord. For permanent deficit, the role of the intraoperative neuromonitoring in the prevention of this outcome is controversial. $3,5,7,8,10$ One patient of our series presented a rapidly evolving paraparesis over a few days. He was operated emergently by thoracoscopy. After the surgery, he presented a definitive paraplegia. We reviewed the case and attributed the worsening to rapid decompensation of myelopathy aggravated by surgical intervention. The risk of rapid decompensation of these lesions is very rare ( $4 \%$ to $15 \%$ of TDH operated ${ }^{6,19}$ ), and, in our opinion, requires 2-stage surgery: first posterior decompression without attempting to resect the herniation and then removal of the lesion by thoracoscopic approach in the days that follow. This strategy was adopted for 6 patients in the series and the clinical outcome was good. ${ }^{20}$

\section{Surgical Resection Technique}

Blood loss has been seldom addressed by previous publications although this surgery clearly has a hemorrhagic risk with losses of up to $3000 \mathrm{~mL} .^{3-10,13,17}$ For this reason, all our surgical procedures are carried out with a cell saver system. Initially, the approach to the epidural space was performed early, by resection of the pedicle, but we are currently using a more anterior approach and the posterior extension to the pedicle is added only if necessary. Figure 2 illustrates the modification of our drilling technique. On the other hand, the use of thrombin gel has proved to be a valuable aid in obtaining rapid hemostasis of epidural bleeding. Therefore, blood loss due to this intervention was reduced from an average of $1100 \mathrm{~mL}$ for the first 18 cases to $413 \mathrm{~mL}$ after modification of the drilling technique. 
TABLE 5. Patients Treated for Giant Thoracic Disc Herniation, Literature Review

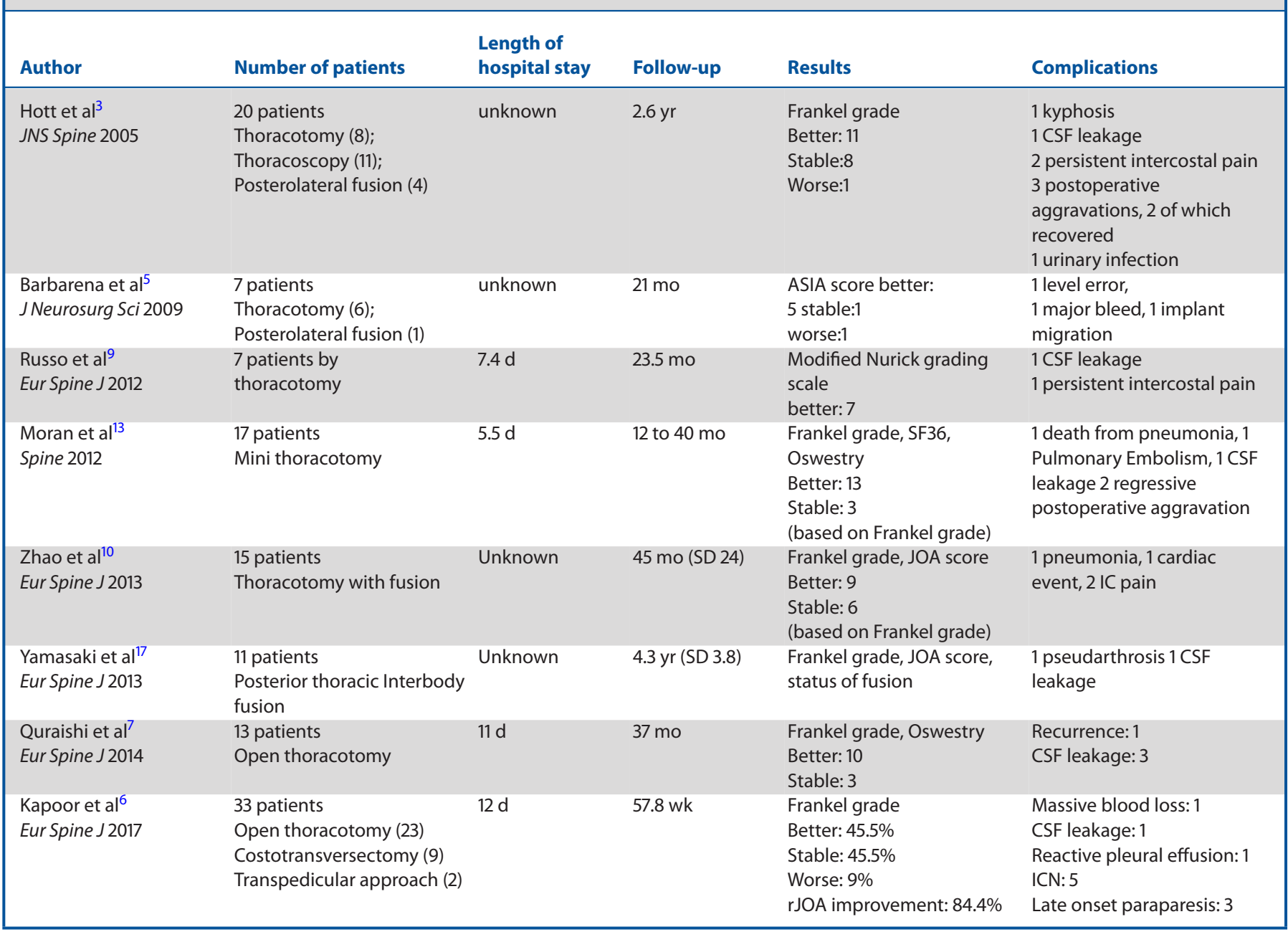

The second limiting factor for the resection of these lesions is the transdural character of the herniation. There is no reliable imaging finding that identifies this condition. The issue of dural repair in the event of a durotomy was raised by Yoshihara ${ }^{18}$ in a literature review and this risk is described by almost all authors who present their results on giant herniations. Several modalities of repair were used during our endoscopic experience. At the beginning of our experience, we used a local pleural flap. Currently, we prefer a fascia lata flap held in place by biological glue. In our series, one-third of the operated herniations were transdural. When the lesion is easily mobilizable we continue the resection and perform a plasty at the end of the procedure according to the above-mentioned technique, then we fill the bony cavities with fat. Sometimes the herniation cannot be dissected from the spinal cord and, in this situation, we prefer to leave the part of the herniation adherent to the spinal cord because of the high risk of neurological aggravation. This was the case for 18 patients who had subtotal or incomplete resection. In these cases, we left the resection chamber free without placing a graft in the cavity in order to promote spinal cord re-expansion. The reappearance of perimedullary CSF spaces was observed in all cases of subtotal resection and in 4 out of 5 cases of incomplete resection. The only case of insufficient decompression benefited from secondary laminoarthrectomy and posterior arthrodesis. These 5 patients showed an improvement in postoperative neurological function at last follow-up.

\section{CONCLUSION}

We present a series of 53 patients operated for giant calcified $\mathrm{TDH}$. These data provide a better understanding of this rare disease, which is technically difficult to treat. We propose 
decision-making criteria and present the long-term evolution of these patients. Preserving neurological function is the main goal of this functional surgery. A subtotal or incomplete resection must be considered if the risk of neurological worsening is high and if spinal decompression has been achieved. Our results suggest that the thoracoscopic approach is a valid therapeutic option in giant symptomatic TDHs.

\section{Disclosure}

The authors have no personal, financial, or institutional interest in any of the drugs, materials, or devices described in this article.

\section{REFERENCES}

1. Wood KB, Garvey TA, Gundry C, Heithoff KB. Magnetic resonance imaging of the thoracic spine. Evaluation of asymptomatic individuals. J Bone Joint Surg. 1995;77(11):1631-1638.

2. Carson J, Gumpert J, Jefferson A. Diagnosis and treatment of thoracic intervertebral disc protrusions. J Neurol Neurosurg Psychiatry. 1971; 34(1):68-77.

3. Hott JS, Feiz-Erfan I, Kenny K, Dickman CA. Surgical management of giant herniated thoracic discs: analysis of 20 cases. JNeurosurg Spine. 2005;3(3):191-197.

4. Al-Mahfoudh R, Mitchell PS, Wilby M, et al. Management of giant calcified thoracic disks and description of the trench vertebrectomy technique. Global Spine J. 2016;6(6):584-591.

5. Barbanera A, Serchi E, Fiorenza V, Nina P, Andreoli A. Giant calcified thoracic herniated disc: considerations aiming a proper surgical strategy/Comment. J Neurosurg Sci. 2009;53(1):9-25.

6. Kapoor S, Amarouche M, Al-obeidi F, U-King-Im JM, Thomas N, Bell D. Giant thoracic discs: treatment, outcome, and follow-up of 33 patients in a single centre. Eur Spine J. 2008;27(7):1555-1566. In press.

7. Quraishi NA, Khurana A, Tsegaye MM, Boszczyk B. M, Mehdian S. M. H. Calcified giant thoracic disc herniations: considerations and treatment strategies. Eur Spine J. 2014;23(S1):76-83.

8. Roelz R, Scholz C, Klingler JH, Scheiwe C, Sircar R, Hubbe U. Giant central thoracic disc herniations: surgical outcome in 17 consecutive patients treated by mini-thoracotomy. Eur Spine J. 2016;25(5):1443-1451.

9. Russo A, Balamurali G, Nowicki R, Boszczyk Bronek Maximilian. Anterior thoracic foraminotomy through mini-thoracotomy for the treatment of giant thoracic disc herniations. Eur Spine J. 2012;21(S2):212-220.

10. Zhao Y, Wang Y, Xiao S, Zhang Y, Liu Z, Liu B. Transthoracic approach for the treatment of calcified giant herniated thoracic discs. Eur Spine J. 2013;22(11):2466-2473.

11. Rosenthal D, Rosenthal R, Simone A. Removal of a protruded thoracic disc using microsurgical endoscopy. Spine. 1994;19(9):1087-1091.

12. Elhadi AM, Zehri AH, Zaidi HA, et al. Surgical efficacy of minimally invasive thoracic discectomy. J Clin Neurosci. 2015;22(11):1708-1713.

13. Moran C, Ali Z, McEvoy L, Bolger C. Mini-open retropleural transthoracic approach for the treatment of giant thoracic disc herniation. Spine. 2012;37(17):E1079-E1084.

14. Brauge D, Madkouri R, Clément R, Reina V, Brauge T, Gaillard S. What are the possibilities of spontaneous resorption of a thoracic disc herniation occupying more than $20 \%$ of the spinal canal in the asymptomatic subject? Comparative study. $J$ Clin Neurosci. 2017;44(1):269-273.

15. Bednarik J, Kadanka Z, Dusek L, et al. Presymptomatic spondylotic cervical myelopathy: an updated predictive model. Eur Spine J. 2008;17(3):421-431.
16. Hur JW, Kim JS, Cho DY, Shin JM, Lee JH, Lee SH. Video-assisted thoracoscopic surgery under O-Arm navigation system guidance for the treatment of thoracic disk herniations: Surgical techniques and early clinical results. J Neurol Surg A Cent Eur Neurosurg. 2014;75(06): 415-421.

17. Yamasaki R, Okuda S, Maeno T, Haku T, Iwasaki M, Oda T. Surgical outcomes of posterior thoracic interbody fusion for thoracic disc herniations. Eur Spine J. 2013;22(11):2496-2503.

18. Yoshihara H. Surgical treatment for thoracic disc herniation. Spine 2014;39(6):E406-E412.

19. Cornips EM, Janssen ML, Beuls EA. Thoracic disc herniation and acute myelopathy: clinical presentation, neuroimaging findings, surgical considerations, and outcome. J Neurosurg Spine. 2011;14(4):520-528.

20. Brauge D, Madkouri R, Reina V, et al. Is there a place for the posterior approach in cases of acute myelopathy on thoracic disc hernia? World Neurosurg. 2017;107(1):744-749.

Supplemental digital content is available for this article at www.operativeneurosurgery-online.com.

Supplemental Digital Content. Video. Example of the surgical procedure.

\section{Acknowledgment}

We would like to the thank Saloua Charni CRA for statistical design and review.

\section{COMMENT}

7 he current work presents a significant clinical series on the treatment of giant thoracic disk herniations. While thoracic disks are less common in presentation, giant, and commonly calcified disks, are even of greater rarity. The size of this patient series is therefore quite substantial.

Large thoracic disks present notable surgical challenges. Commonly, patients have progressive myelopathy. Even subtle manipulation of the cord may lead to spinal cord injury. This places a significant importance on choosing the appropriate surgical corridor. Costotransversectomy and lateral extracavitary approaches allow the surgeon ventral access to the area of spinal compression. This decreases the risk of cord manipulation. The endoscopic approach presented in this work illustrates an excellent example of a ventral approach to these disk herniations. The bony anatomy removed upon approach is illustrated through both axial CT images as well as CT reconstructions. These presented images are critical, as the step-wise removal of bony anatomy is critical to the safe execution of this operation.

The authors should be applauded for this case series. This is a challenging pathology, for neurosurgeons of all levels of skill or experience. This work illustrates an important method for treating this challenging pathology.

Zachary A. Smith Chicago, Illinois 